\title{
Modeling the impact of thinning on height development of dominant and codominant loblolly pine trees
}

\author{
Mahadev SHARMa ${ }^{\text {a* }}$, Michael SMITH ${ }^{\mathrm{b}}$, Harold E. BURKHART ${ }^{\mathrm{c}}$, Ralph L. AMATEIS $^{\mathrm{c}}$ \\ a Ontario Forest Research Institute, Ministry of Natural Resources, 1235 Queen Street E, Sault Ste Marie, P6A 2E5 ON, Canada \\ ${ }^{\mathrm{b}}$ White Earth Indian Reservation in White Earth, Minnesota, USA \\ ${ }^{\mathrm{c}}$ Department of Forestry, Virginia Polytechnic Institute and State University, Blacksburg, VA 24061
}

(Received 24 June 2005; accepted 3 October 2005)

\begin{abstract}
Data collected from loblolly pine thinning study plots established in plantations on cutover, site-prepared lands were used to evaluate thinning impact on height growth of dominant and codominant loblolly pine trees. Height growth was reduced initially by thinning but was increased after 3 years following thinning. The average total height of dominant and codominant trees in thinned stands exceeded its counterpart in unthinned stands 12 years after thinning. Initial growth response to thinning was less at older stand ages than at younger ages. A model was constructed to characterize the development of height in thinned and unthinned stands. This model reflects the initial suppression of dominant and codominant height growth followed by an acceleration as a result of thinning.
\end{abstract}

site index / thinning shock / thinning response function / Pinus taeda

Résumé - Modélisation de l'impact de l'éclaircie sur le développement en hauteur des arbres dominants et codominants chez Pinus taeda L. Des données récoltées dans des dispositifs expérimentaux d'étude des éclaircies, installés dans des plantations de Pinus taeda, ont été utilisées pour évaluer l'impact de l'éclaircie sur la croissance en hauteur des arbres dominants et co-dominants. La croissance en hauteur a été initialement réduite par éclaircie, mais s'est accrue dans les 3 ans suivant l'éclaircie. La moyenne de la hauteur totale des arbres dominants et codominants dans les peuplements éclaircis est supérieure à celle des arbres dominants et codominants des peuplements non éclaircis, 12 ans après l'éclaircie. La réponse initiale en termes de croissance à l'éclaircie était plus faible dans les vieux peuplements que dans les peuplements jeunes. Un modèle a été construit pour caractériser l'évolution de la croissance en hauteur dans les peuplements éclaircis et les peuplements non éclaircis. Ce modèle reflète l'effet initial dépressif de l'éclaircie sur la croissance des arbres dominants et codominants suivi d'une accélération comme résultat de l'effet d'éclaircie.

site index / effet de l'éclaircie / fonctions de réponse de l'éclaircie / Pinus taeda

\section{INTRODUCTION}

In order to achieve forest management objectives, individual tree and stand developments are manipulated by applying an array of silvicultural treatments. Thinning is one of the most common and effective silvicultural treatments for regulating individual tree and stand growth. There are situations, however, where initial responses to thinning are not always positive. Reductions in height or diameter growth, chlorotic foliage, and damage or mortality associated with increased exposure after thinning are examples of negative responses. These negative responses, individually or collectively, are referred to as "thinning shock" [6].

It is generally accepted that mean dominant stand height is not strongly influenced by changes in stand density. This is a key assumption underlying the use of site index, defined as the top height (mean height of dominant and codominant trees) of a stand at a specified (index) age, as an indicator of site quality (productivity). However, previous studies by

\footnotetext{
*Corresponding author: mahadev.sharma@mnr.gov.on.ca
}

Ginn et al. [5] and Peterson et al. [10] on loblolly pine (Pinus taeda L.) and by Harrington and Reukema [6], Miller and Reukema [9], and Crown et al. [4] on Douglas-fir (Pseudotsuga menziesii Franco) indicate that height growth in a stand is affected by thinning.

If thinning has an impact on the height growth, it is important that the thinning response be incorporated in growth and yield prediction models. Including response to thinning may improve understanding of management effects and help forest managers make accurate decisions on appropriate management regimes. In the past, efforts have been made to incorporate the response of thinning in growth and yield models implicitly or explicitly. The individual tree growth simulation model, PTAEDA2 [3], is an example where response to thinning is implicit through changes in each tree's competitive status.

Short and Burkhart [11] and Liu et al. [7] described changes in crown ratio as an explicit function of a generalized thinning response variable. The thinning response variable can account for various factors which affect response to thinning, such as intensity of thinning, age of the stand at the time 
of thinning, and the time elapsed since thinning. Similarly, Amateis et al. [1] developed separate diameter increment models for loblolly pine trees grown in thinned and unthinned stands.

Smith [13] developed a height growth model for loblolly pine trees grown in thinned and unthinned stands by explicitly utilizing the generalized thinning response variable presented later by Liu et al. [7]. The performance of the model, however, was not fully satisfactory since the data used to fit the model did not include a time span long enough to differentiate the stand development following thinning.

A height growth model that performs well under negative as well as positive effects of variable thinning intensity has not been advanced. Here, we present results from a study aimed at analyzing both initial and long-term responses to different intensities of thinning for height of dominant and codominant loblolly pine trees grown in plantations on cutover, siteprepared areas. We then develop a height growth equation accounting for thinning response over time.

\section{MATERIEL AND METHODS}

\subsection{Data}

The data used in this study were collected from permanent plots established in thinned and unthinned loblolly pine plantations on cutover, site-prepared lands [2]. During the dormant seasons of 19801981 and 1981-1982, permanent plots were established in planted stands of loblolly pine (Pinus taeda L.) through the native range of the species in the southeastern United States at 186 locations. At the time of initial plot establishment, the stands averaged 14 years in age (defined as years since planting). Plot locations ranged from Maryland south to Georgia and west to East Texas (latitude from approximately $30^{\circ} \mathrm{N}$ to $38^{\circ} \mathrm{N}$ and longitude from around $75^{\circ} \mathrm{W}$ to $95^{\circ} \mathrm{W}$ ). At each location, three treatment plots were installed: an unthinned control, a lightly thinned, and a heavily thinned plot.

Thinnings were from below with occasional larger trees removed where damage or spacing considerations were a factor. Approximately 30 and $50 \%$ of total basal area was removed from the lightly and heavily thinned plots, respectively [2]. A second thinning was applied in roughly half of the thinned plots during the 1992-1994 dormant seasons, 12 years after plot establishment.

Diameter at breast height (dbh), total height, and crown class (dominant, codominant, intermediate, and suppressed) information was collected on all trees every three years since plot establishment. Crown class determination was made by field personnel according to the crown class definitions of Smith [12]. At the time of this study, six remeasurements had been completed.

Summary statistics for the total height of all trees for each treatment at each measurement are presented in Table I. At the end of the sixth remeasurement, only 84 stands out of 186 (41 once thinned and the rest twice thinned) remained and the rest were damaged by flood, fire, disease and/or other activities. Data from once thinned stands were set aside for parameter estimation and the rest were used for model evaluation.

\subsection{Thinning impact on height growth}

In order to examine the thinning impact on the growth of dominant and codominant loblolly pine trees, the mean value of total height of dominant and codominant trees was calculated for each unthinned and once thinned stand at each location (site) for each remeasurement. Trees that were broken, diseased or damaged at any point in the study were excluded from this analysis. Also, plots in which the numbers of dominant and codominant trees were fewer than 5 were not included in the analysis. Unless otherwise specified, the term "mean" used in this paper refers to the arithmetic mean. Similarly, "height" represents the total height of dominant and codominant trees.

Mean heights in lightly and heavily thinned stands were compared by conducting paired $t$-tests on mean height of dominant and codominant trees across sites by remeasurement (Tab. II), with their counterparts in unthinned stands. $P$-values in Table II indicate that the plots with different levels of thinning were very similar in terms of total height of dominant and codominant trees at plot establishment.

At the first remeasurement ( 3 years after plot establishment), mean height was significantly smaller in heavily thinned stands than in unthinned stands $(p<0.05)$. Afterward, the difference in mean height between unthinned and heavily thinned stands diminished gradually. By the fifth remeasurement, the mean height was greater (although not significantly) in heavily thinned stands than in unthinned stands. The mean height became significantly greater in heavily thinned stands than in unthinned stands $(p<0.05)$ by the time of sixth remeasurement. Mean height in heavily thinned stands, however, was not significantly different from its counterpart in lightly thinned stands across the measurements.

In the case of lightly thinned stands, the mean height was not significantly different from the mean height in unthinned stands. Nevertheless, the difference in mean heights between unthinned and lightly thinned stands followed the pattern of the difference in mean heights between unthinned and heavily thinned stands over time.

It is obvious from Table II that the maximum negative impact of thinning on height growth occurred around the first remeasurement (3 years after thinning) and recovery took about 6-9 years thereafter. Exact times for the maximum negative thinning impact and the growth recovery for height could not be obtained from the data since the stands were measured every three years following thinning.

\subsection{Model development}

Two assumptions were made for developing a model to predict mean height of dominant and codominant trees by stand age. The first is that height growth approaches zero as height approaches a maximum limit [8] and the second is that growth is proportional to the thinning response function $(T R F)$. Mathematically:

$$
\frac{\mathrm{d} Y}{\mathrm{~d} A}=\alpha \frac{Y}{A}\left(1-\frac{Y}{M}\right)(T R F)
$$

where $Y$ is average height, $A$ is age in years, $M$ is an asymptotic maximum parameter, $T R F$ is some function representing a thinning effect, and $\alpha$ is a proportionality constant. Rearranging the terms of Equation (1) gives:

$$
\frac{\mathrm{d} Y}{Y\left(1-\frac{Y}{M}\right)}=\alpha(\text { TRF }) \frac{\mathrm{d} A}{A}
$$

Integrating Equation (2) results in:

$$
\int \frac{\mathrm{d} Y}{Y\left(1-\frac{Y}{M}\right)}=\alpha \int(T R F) \frac{\mathrm{d} A}{A}
$$


Table I. Summary statistics for total height of all trees for each treatment (thinning) plot at each measurement.

\begin{tabular}{|c|c|c|c|c|c|c|c|c|c|}
\hline \multirow[b]{3}{*}{ Measurement* } & \multicolumn{3}{|c|}{ Unthinned } & \multicolumn{3}{|c|}{ Lightly thinned } & \multicolumn{3}{|c|}{ Heavily thinned } \\
\hline & \multirow{2}{*}{ Trees/ha } & \multicolumn{2}{|c|}{ Height } & \multirow{2}{*}{ Trees/ha } & \multicolumn{2}{|c|}{ Height } & \multirow{2}{*}{ Trees/ha } & \multicolumn{2}{|c|}{ Height } \\
\hline & & Mean (m) & Stdev (m) & & Mean (m) & $\begin{array}{l}\operatorname{Stdev}(\mathrm{m}) \\
\end{array}$ & & Mean (m) & $\begin{array}{l}\operatorname{Stdev}(\mathrm{m}) \\
\end{array}$ \\
\hline 0 & 1443 & 11.38 & 3.63 & 1407 & 11.38 & 3.68 & 1409 & 11.37 & 3.64 \\
\hline 1 & 1363 & 13.10 & 3.51 & 836 & 13.59 & 3.49 & 636 & 13.70 & 3.51 \\
\hline 2 & 1220 & 14.57 & 3.36 & 793 & 15.16 & 3.32 & 605 & 15.28 & 3.34 \\
\hline 3 & 999 & 15.80 & 3.21 & 673 & 16.39 & 3.08 & 516 & 16.58 & 3.07 \\
\hline 4 & 750 & 17.25 & 3.21 & 548 & 17.78 & 3.05 & 421 & 18.10 & 3.04 \\
\hline 5 & 555 & 18.80 & 3.31 & 353 & 19.58 & 3.08 & 268 & 19.91 & 3.13 \\
\hline 6 & 436 & 20.00 & 3.34 & 290 & 20.74 & 3.12 & 223 & 20.97 & 3.08 \\
\hline
\end{tabular}

* $0=$ plot establishment, $1=3$ years after plot establishment, $2=6$ years after plot establishment, etc.

Table II. $P$ values of paired $t$-tests for mean height of dominant and codominant trees in lightly and heavily thinned plots of each stand compared with unthinned plots by remeasurement.

\begin{tabular}{lcccccc}
\hline \multirow{2}{*}{ Measurement* } & \multicolumn{2}{c}{ Unthinned vs. lightly thinned } & \multicolumn{2}{c}{ Unthinned vs. heavily thinned } & \multicolumn{2}{c}{ Lightly thinned vs. heavily thinned } \\
\cline { 2 - 6 } & Difference $(\mathrm{m})$ & $p$-value & Difference $(\mathrm{m})$ & $p$-value & \multicolumn{2}{c}{ Difference $(\mathrm{m})$} \\
\hline 0 & 0.01 & 0.936 & 0.03 & 0.719 & 0.02 & 0.832 \\
1 & 0.12 & 0.450 & 0.23 & 0.022 & 0.11 & 0.355 \\
2 & 0.02 & 0.868 & 0.16 & 0.096 & 0.13 & 0.339 \\
3 & -0.02 & 0.894 & 0.08 & 0.448 & 0.10 & 0.460 \\
4 & -0.03 & 0.838 & 0.01 & 0.918 & 0.04 & 0.754 \\
5 & -0.10 & 0.552 & -0.15 & 0.210 & -0.05 & 0.727 \\
6 & -0.33 & 0.113 & -0.32 & 0.027 & 0.01 & 0.958 \\
\hline
\end{tabular}

$* 0=$ plot establishment, $1=3$ years after plot establishment, $2=6$ years after plot establishment, etc.

As far as TRF is concerned, Short and Burkhart [11] introduced a $T R F$ function in a crown height development model for loblolly pine trees as:

$$
T R F=\left(I^{\frac{A_{\mathrm{t}}}{\mathrm{A}}}\right)^{r}
$$

where $I$ is the ratio of after to before thinning basal area, $A$ is the stand age, $A_{\mathrm{t}}$ is the stand age at the time of thinning $\left(A>A_{\mathrm{t}}\right)$, and $r$ is the rate parameter corresponding to thinning response. In order to account for the thinning response in the beginning, the value of $r$ should be less then zero. In that case, Equation (4) is a monotonically decreasing function over time. This implies that the response of stand or tree characteristics is maximized at the time of thinning and diminishes thereafter. Biologically, however, there should be no immediate response at the time of thinning.

Therefore, Liu et al. [7] presented another TRF:

$$
T R F=I^{n}\left(\frac{k\left(A-A_{t}\right)-\left(A-A_{t}\right)^{2}}{A^{2}}\right)
$$

where $k$ is a parameter, known as the duration parameter, and the other variables are as defined earlier. The units of $k$ are years. As a result, the rate parameter, $r$, becomes unitless.

Equation (5) has the following properties: the response to thinning (1) starts at zero $(T R F=1)$ at the time of thinning and becomes negative; (2) reaches a maximum after some time $t_{\mathrm{m}}$ since thinning; and (3) the growth in thinned stands exceeds the growth in unthinned stands after $t_{\mathrm{m}},\left(A-A_{\mathrm{t}}\right)$ equals the duration parameter, $k$. It can be easily seen that the maximum negative response to thinning occurs at

$$
t_{\mathrm{m}}=\frac{k A_{\mathrm{t}}}{k+2 A_{\mathrm{t}}}
$$

years after thinning. It is obvious that the age of maximum response depends on the age of the stand at time of thinning $\left(A_{\mathrm{t}}\right)$ and $k$. Details of the characteristics of this TRF can be found in Liu et al. [7].

Equation (5) has all the properties required to represent a thinning response function $(T R F)$ for the height growth of loblolly pine trees. Therefore, Equation (5) was adopted as a thinning response function $(T R F)$ in this study. Equation (3) with this $T R F$ function becomes:

$$
\int \frac{\mathrm{d} Y}{Y\left(1-\frac{Y}{M}\right)}=\alpha \int I^{\prime\left(\frac{k\left(A-A_{t}\right)-\left(A-A_{t}\right)^{2}}{A^{2}}\right)} \frac{\mathrm{d} A}{A}
$$

The left hand side of Equation (7) can be evaluated analytically. The height growth between any two points $Y_{1}$ and $Y_{2}$ (corresponding to ages $A_{1}$ and $A_{2}$, respectively) can be computed from:

$$
\int_{Y_{1}}^{Y_{2}} \frac{\mathrm{d} Y}{Y\left(1-\frac{Y}{M}\right)}=\log \left(\frac{Y_{2}\left(M-Y_{1}\right)}{Y_{1}\left(M-Y_{2}\right)}\right)
$$

Thus, the function of height growth, $\log \left(\frac{Y_{2}\left(M-Y_{1}\right)}{Y_{1}\left(M-Y_{2}\right)}\right)$ between stand ages $A_{1}$ and $A_{2}$ can be written as:

$$
\log \left(\frac{Y_{2}\left(M-Y_{1}\right)}{Y_{1}\left(M-Y_{2}\right)}\right)=\alpha \int_{A_{1}}^{A_{2}} I^{\prime}\left(\frac{k\left(A-A_{t}\right)-\left(A-A_{t}\right)^{2}}{A^{2}}\right) \frac{\mathrm{d} A}{A}
$$

The right hand side of Equation (8), however, does not have a closed form solution. Therefore, it must be evaluated numerically. Tang et al. [14] introduced a two-stage regression method to solve unidentifiable simultaneous equations in system ecology based on an errorin-variable model. To make the method more applicable in a complex 
situation, Tang and Wang [15] presented a parameter estimation algorithm that estimates the parameters and evaluates the integral simultaneously. Therefore, this algorithm was adopted to solve Equation (8) and estimate the parameters. In order to use the algorithm, however, the asymptotic value of height $(\mathrm{M})$ must be known so that the dependent variable, $\log \left(\frac{Y_{2}\left(M-Y_{1}\right)}{Y_{1}\left(M-Y_{2}\right)}\right)$, can be calculated for each observation. The height growth equation presented by McDill and Amateis [8], i.e. Equation (3) without $T R F$, was used to estimate the asymptotic value of height.

Each observation used in fitting Equation (8) was calculated using an initial measurement and the subsequent remeasurement. The initial measurement was used to define $Y_{1}$ and $A_{1}$, and the ending measurement was used to define $Y_{2}$ and $A_{2}$. As a result, all measurements except the first and last belonged to two observations - as the initial measurement in one observation and as the ending measurement in another. This resulted in six observations per plot. Equation (8) was fitted to the data set obtained from the stands that were thinned only at plot establishment using the algorithm developed by Tang and Wang [15].

Equation (8) for height growth was evaluated by comparing its performance with the height growth model presented by Smith [13]. Smith's model was the following:

$$
H=\exp \left(\ln \left(H_{0}\right)\left(A_{0} / A\right)^{\beta_{0}} e^{\beta_{1}\left(\frac{T R F}{A}-\frac{T R F_{0}}{A_{0}}\right)}\right)
$$

where, $\mathrm{H}$ and $H_{0}$ are heights and $T R F$ and $T R F_{0}$ are thinning response values at ages $A$ and $A_{0}$, respectively, and $\beta_{0}$ and $\beta_{1}$ are parameters. Equation (9) was also fitted to the same data set using the NLIN procedure in SAS. Evaluation was performed by calculating bias in estimating heights under different thinning conditions for the estimation data set.

Further evaluation of the height growth model was performed by calculating bias in estimating heights for the data from twice thinned stands which were set aside for model validation. In order to avoid the confounding effect of second thinning, only heights measured up to the fourth measurement were used for the evaluation.

\section{RESULTS AND DISCUSSION}

The estimate for asymptotic height obtained from Equation (3) without TRF was $38 \mathrm{~m}$. Similarly, estimated values of parameters for Equation (8) corresponding to $\alpha, r$, and $k$ were $1.2714,1.7655$, and 4.5631 , respectively. To ensure that the solution represents a global rather than local minimum, multiple initial values of the model parameters were provided for the fits. The predicted heights using this set of parameters at different thinning level, however, resulted in a time period of 8 years for height recovery after thinning, which is less than the approximately 13 years indicated by the observed data.

Therefore, a value of $k$ was sought in Equation (8) that results in the recovery period of approximately 13 years. By setting different values of $k$ in Equation (8) and running the program to estimate other parameters, a value of $k$ equal to 7 resulted in the recovery period of around 13 years. Estimates for other parameters, $\alpha$ and $r$, corresponding to this value of $k$ were 1.2949 and 2.0488 , respectively.

It should be noted that the $T R F$ parameters in Equation (8) do not have the same interpretation as the parameters in Equa- tion (5). The value of the duration parameter, $k$, in Equation (5), for example, represents the recovery period for height after thinning. On the other hand, $k=7$ in Equation (8) results in the recovery period of approximately 13 years after thinning. Therefore, the parameter $k$ in Equation (8) cannot be directly interpreted as the duration parameter as opposed to in Equation (5). This difference in the interpretation of these values results from estimating the parameters and evaluating the integral simultaneously. The parameter $k$ in Equation (8) is under the integral and hence is evaluated upon integration. On the other hand, Equation (5) alone is interpreted without any further evaluation.

The positive sign of the thinning response rate parameter, $r$, in Equation (8) indicates that trees in plantations under thinning would eventually have greater heights than the trees in unthinned stands. The heavier the thinning, the greater is the response. Similarly, the positive value of $k$ indicates that height growth initially has a negative response to thinning, starting at zero at the time of thinning and subsequently reaching a negative maximum.

The time to the maximum negative response $\left(t_{\mathrm{m}}\right)$ can be calculated by replacing $k$ in Equation (6) with its estimate that is 13 . Assuming that the stands were thinned at age 11 years (average age of thinning for the stands that survived through the 6th remeasurement), the maximum negative thinning impact on the height growth occurs 4 years after thinning. After this point, the height growth response to thinning turns positive and increases over time. The mean height in thinned stands crosses over the mean height in unthinned stands approximately 13 years after thinning.

Evaluation of height growth models was carried out by calculating bias (observed - predicted) in estimating heights of dominant and codominant trees for each stand at each remeasurement. Average bias was computed across the stands for each treatment (thinning) at each remeasurement for both fitting and validation data sets (Tab. III). It is clear that Equation (8) is superior to Equation (9) in terms of bias for all thinning levels.

Further evaluation of Equation (8) was performed by generating height growth curves for the thinned stands with intensities of 0,30 , and $50 \%$ percent basal area removed at age 11 years. These curves were constructed using the average dominant height $(11 \mathrm{~m})$ at plot establishment (Fig. 1). Trees are taller in unthinned stands than in thinned stands between ages 11 and 24 years: the heavier the intensity of thinning the shorter the trees in the stand during this period. As expected, the growth pattern reversed after the time approximately 13 years following thinning and total height is greater in thinned stands than in unthinned stands after that time. This growth pattern continues through the rest of the observation.

Height growth curves were also produced using Equation (8) for trees in thinned (50\% basal area removed) and unthinned stands at two different site productivities. Mean heights of the dominant and codominant trees at lower and higher site productivities at the time of thinning at age 11 years were assumed to be 8 and $12 \mathrm{~m}$, respectively (Fig. 2). The negative response to thinning (the thinning shock) is slightly greater for the trees at higher site than at lower site 
Table III. Mean bias (observed - predicted) for height (m) of loblolly pine trees at different measurements for models (8) and (9) using fit and validation data.

\begin{tabular}{|c|c|c|c|c|c|c|}
\hline \multirow{2}{*}{ Measurement* } & \multicolumn{2}{|c|}{ Unthinned stands } & \multicolumn{2}{|c|}{ Lightly thinned stands } & \multicolumn{2}{|c|}{ Heavily thinned stands } \\
\hline & Equation (8) & Equation (9) & Equation (8) & Equation (9) & Equation (8) & Equation (9) \\
\hline \multicolumn{7}{|l|}{ Fit data set } \\
\hline 1 & 0.077 & -0.097 & -0.134 & 0.029 & -0.022 & 0.106 \\
\hline 2 & -0.171 & -0.145 & -0.031 & -0.016 & -0.010 & -0.003 \\
\hline 3 & -0.056 & 0.017 & -0.023 & -0.016 & -0.005 & -0.021 \\
\hline 4 & 0.094 & 0.173 & 0.028 & 0.059 & 0.041 & 0.045 \\
\hline 5 & 0.161 & 0.217 & 0.098 & 0.138 & 0.110 & 0.149 \\
\hline 6 & 0.031 & 0.023 & 0.067 & 0.106 & -0.053 & -0.060 \\
\hline \multicolumn{7}{|c|}{ Validation data set } \\
\hline 1 & -0.241 & -0.251 & -0.124 & -0.145 & -0.142 & -0.086 \\
\hline 2 & -0.125 & -0.060 & 0.072 & 0.138 & 0.052 & 0.075 \\
\hline 3 & 0.032 & 0.123 & 0.088 & 0.125 & -0.066 & 0.039 \\
\hline 4 & 0.040 & 0.126 & 0.004 & 0.041 & 0.012 & 0.114 \\
\hline
\end{tabular}

$* 1=3$ years after plot establishment, $2=6$ years after plot establishment, etc.
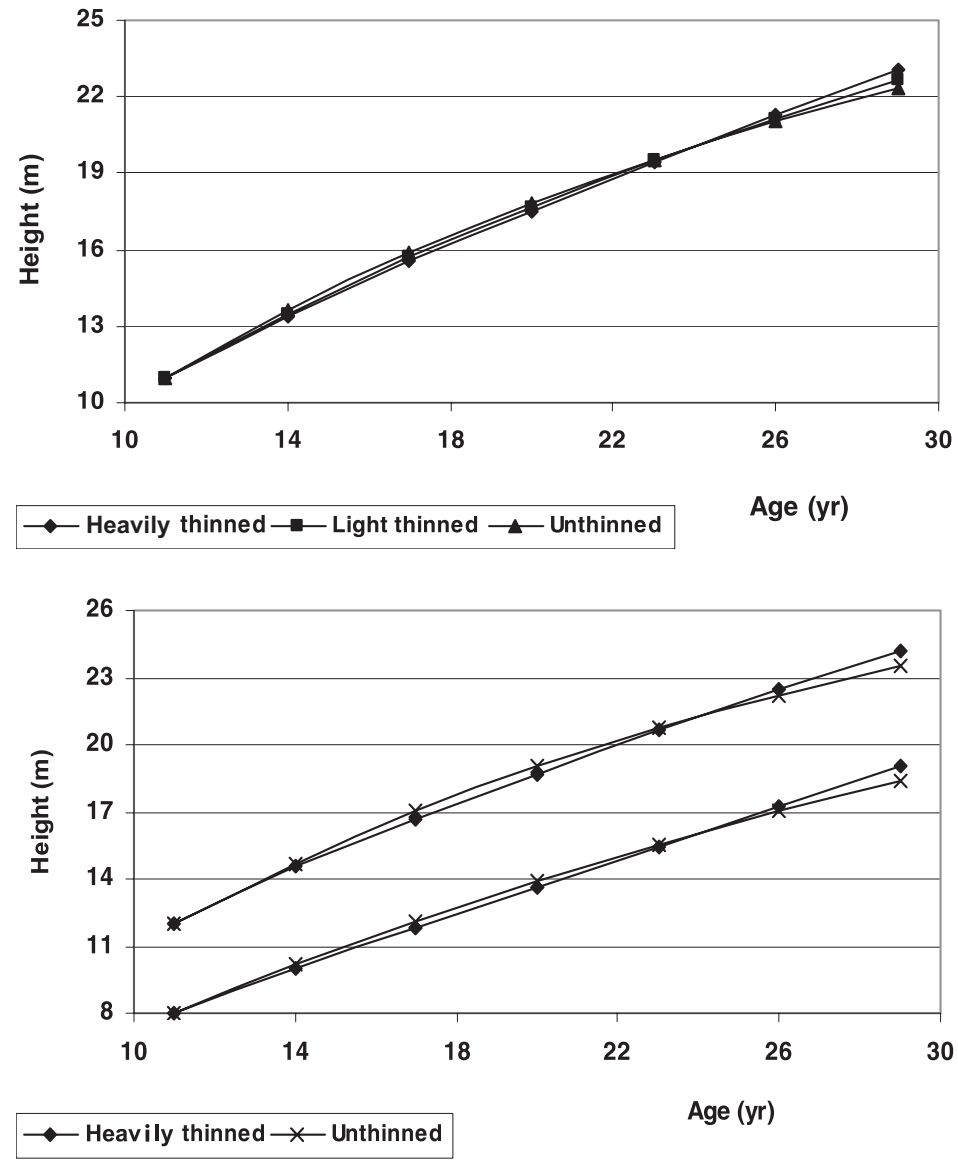

Figure 1. Height curves generated by Equation (8) for unthinned, lightly thinned, and heavily thinned stands using initial height of $11 \mathrm{~m}$ at age 11 years.
Figure 2. Height curves generated by Equation (8) for heavily thinned and unthinned stands at two sites of different productivities using a thinning intensity of $50 \%$ basal area removed and a thinning age of 11 years. quality. After the crossover between heights in thinned and unthinned stands, the difference in heights between unthinned and thinned stands is greater for lower than for higher site qualities.

Several researchers in the past have also reported the negative and positive thinning impacts on the stand growth. The thinning impact on height growth of Douglas-fir trees reported by Harrington and Reukema [6] was similar to that described here. Miller and Reukema [9] and Crown et al. [4] also reported reduced height growth of Douglas-fir trees following thinning.

Peterson et al. [10] found that loblolly pine trees in thinned stands quickly expanded their crowns horizontally starting the year following thinning along with the reduction in height growth. They also found that the crown expansion approached its maximum 6 years after thinning. 
Similarly, Ginn et al. [5] reported decreased height growth and increased live crown diameter growth of loblolly pine trees during the first year after thinning, followed by increased stem diameter growth during the second year. However, none of these studies reported the crossover between heights in thinned and unthinned stands. This may be because the duration of time of the stand development they observed following thinning was not long enough to exhibit the full effect of the thinning.

There have been efforts made at explaining stand development following thinning. In an attempt to describe crown development of loblolly pine trees after thinning, Liu et al. [7] argued that there should be no immediate thinning response on height growth. The response to thinning should begin at zero and increase to some maximum as the crowns of the residual trees respond to the extra growing space and additional sunlight. The response should diminish after crown closure and approach the unthinned condition. Ginn et al. [5] attributed the decrease in height growth of loblolly pine trees to a redistribution of photosynthate from height growth to the expansion of the lower crown after thinning.

Equation (8) can be applied to estimate height $\left(Y_{2}\right)$ at age $A_{2}$ if the height $\left(Y_{1}\right)$ at age $A_{1}$, basal area ratio $(I)$, and the age at the time of thinning $\left(A_{t}\right)$ are known. Since the parameters $\alpha, r$ and $k$ known (estimated values), the right hand side of the equation can be evaluated by using computer software (e.g. Mathematica). $Y_{2}$ can then be calculated as:

$$
Y_{2}=\frac{M Y_{1} \exp (c)}{M-Y_{1}(1-\exp (c))}
$$

where, $c$ represents the right hand side of Equation (8) for a given set of variables. The integral of Equation (8) can also be computed online [16].

\section{CONCLUSIONS}

This study shows that height growth of dominant and codominant loblolly pine trees is affected by thinning. Within the range of removals contained in this data set, the heavier the thinning the greater is the response. Height growth is initially reduced by thinning resulting in shorter trees in thinned stands than in unthinned stands. After the decrease in height growth reaches its maximum, growth begins to increase yielding taller trees in thinned stands than in unthinned stands at older ages. However, the initial thinning response at an older stand age is not as great as thinning response at an earlier age. Moreover, the light thinning applied in this study was not intense enough to significantly affect height growth even at younger ages.

Although the impact of thinning on dominant height development of loblolly pine plantations is relatively small, and in many circumstances the differences can be safely ignored, understanding and quantifying the nuances of thinning on stand development can potentially aid in improving growth estimates and management prescriptions.
Acknowledgements: This study was supported by the Loblolly Pine Growth and Yield Research Cooperative at Virginia Polytechnic Institute and State University. The authors are grateful to Shouzheng Tang for his assistance in using the parameter estimation algorithm to estimate the parameters in the model.

\section{REFERENCES}

[1] Amateis R.L., Burkhart H.E., Walsh T.A., Diameter increment and survival equations for loblolly pine trees growing in thinned and unthinned plantations on cutover, site-prepared lands, South. J. Appl. For. 13 (1989) 170-174.

[2] Burkhart H.E., Cloeren D.C., Amateis R.L., Yield relationships in unthinned loblolly pine plantations on cutover, site-prepared lands, South. J. Appl. For. 9 (1985) 84-90.

[3] Burkhart H.E., Farrar K.D., Amateis R.L., Daniels R.F., Simulation of individual tree growth and stand development in loblolly pine plantations on cutover, site-prepared areas, School of Forestry and Wildlife Resources, Virginia Polytechnic Institute and State University, Publication FWS-1-87, Blacksburg, VA, 1987, 47 p.

[4] Crown M., Quenet R.V., Layton C., Fertilization and thinning effects on a Douglas-fir ecosystem at Shawnigan Lake: 3-year growth response, Can For Serv Rep BC-X-152, Victoria, BC, 1977, 36 p.

[5] Ginn S.H., Seiler J.R., Cazell B.H., Kreh R.E., Physiological and growth responses of eight-year-old loblolly pine stands to thinning, For. Sci. 37 (1991) 1030-1040

[6] Harrington C.A., Reukema D.L., Initial shock and long-term stand development following thinning in a Douglas-fir plantation, For. Sci. 29 (1983) 33-46.

[7] Liu J., Burkhart H.E., Amateis R.L., Projecting crown measures for loblolly pine trees using a generalized thinning response variable, For. Sci. 41 (1995) 43-53.

[8] McDill M.E., Amateis R.L., Measuring forest site quality using the parameters of a dimensionally compatible height growth function, For. Sci. 38 (1992) 409-429.

[9] Miller R.E., Reukema D.L., Urea fertilizer increases growth of 20year-old thinned Douglas-fir on a poor quality site. USDA Forest Serv Res Note PNW-291, Pac Northwest Forest and Range Exp Stn, Portland, Oreg., 1977, 8 p

[10] Peterson J.A., Seiler J.R., Nowak J., Ginn S.E., Kreh R.E., Growth and physiological responses of young loblolly pine stands to thinning, For. Sci. 43 (1997) 529-534.

[11] Short E.A.III, Burkhart H.E., Predicting crown-height increment for thinned and unthinned loblolly pine plantations, For. Sci. 38 (1992) 594-610.

[12] Smith D.M., The Practice of Silviculture, 7th ed., John Wiley and Sons, Inc., New York, 1962, 578 p.

[13] Smith M.C., Diameter and height increment and mortality functions for loblolly pine trees in thinned and unthinned plantations, M.S. thesis, Department of Forestry, Virginia Polytechnic Institute and State University, Blacksburg, VA, 1994, 138 p.

[14] Tang S., Li Y., Wang Y., Simultaneous equations, error-in-variable models, and model integration in systems ecology, Ecol. Model. 142 (2001) 285-294.

[15] Tang S., Wang Y., A parameter estimation program for the error-invariable model, Ecol. Model. 156 (2002) 225-236.

[16] Waner S., Costenoble R. Copyright 1995, http://people.hofstra edu/faculty/Stefan_Waner/RealWorld/integral/integral.html. 